\title{
Absence of Tissue Plasminogen Activator Gene or Activity Impairs Mouse Cerebellar Motor Learning
}

\author{
Nicholas W. Seeds, Mark E. Basham, and Jayne E. Ferguson \\ Department of Biochemistry and Molecular Genetics, University of Colorado Health Sciences Center, Denver, Colorado 80262
}

\begin{abstract}
Motor learning is thought to involve modulation of synaptic inputs in the cerebellar cortex, including granule neuron/Purkinje neuron contacts. During a complex motor task requiring mice to walk across irregularly spaced pegs, cerebellar granule neurons show a rapid and transient induction of mRNA for the extracellular protease tissue plasminogen activator (tPA). This induction of tPA mRNA is cerebellar specific, is not seen in the cerebella of exercised or stressed animals, and is distinct from simple performance phenomena. Knock-out mice lacking the tPA gene show a significant reduction in both rate and extent of learning. Furthermore, blocking tPA activity during training dramatically impaired motor learning. Thus, tPA plays an important role in motor learning, in which tPA may facilitate remodeling of the active synaptic zone.
\end{abstract}

Key words: tPA mRNA; protease inhibitor; PAI-1; granule neuron; synaptic plasticity; memory

\section{Introduction}

Long-term memory requires the synthesis of new proteins, which are thought to bring about structural changes in synaptic connections within the brain (for review, see Bailey and Kandel, 1993). The cerebellar cortex has been implicated as an important area of plasticity for motor learning. Black et al. (1990) have shown an increase in the number of synapses per Purkinje cell in the molecular layer of the cerebellar cortex of rats trained to perform complex motor tasks, whereas the number of these parallel fiber synapses on Purkinje neurons does not change in animals subjected to voluntary exercise. These synaptic changes are related to the learning of a specific motor task and not merely increased synaptic activity.

The plasminogen activators (PA) are serine proteases that play an important role in tissue remodeling and cell migration (Dano et al., 1985; Saksela and Rifkin, 1988; Seeds et al., 1999); therefore, they are potential candidate molecules to participate in synaptic remodeling. PA are secreted by neurons during axonal growth and regeneration and then bind with high affinity to the surface of the growth cone, where they are poised to facilitate nerve outgrowth through a tissue matrix (Krystosek and Seeds, 1981; Pittman et al., 1989; Verrall and Seeds, 1989; McGuire and Seeds, 1990). Tissue plasminogen activator (tPA) is the primary PA in brain, being expressed at high levels in embryonic brain regions undergoing cell migration and tissue remodeling (Friedman and Seeds, 1994, 1995). In general, tPA levels are greatly reduced in

\footnotetext{
Received April 3, 2003; revised June 5, 2003; accepted June 17, 2003.

This work was supported in part by National Institutes of Health Grants NS-09818 and NS-44129 to N.W.S. and National Institute of Mental Health-National Research Service Award MH12142 to M.E.B. We thank Dr. Peter Carmeliet for his gift of the initial tPA knock-out mice and the expert technical assistance of Lisa Beckelheimer and Lisa Akison.

Correspondence should be addressed to Dr. Nicholas W. Seeds, Department Biochemistry and Molecular Genetics, UCHSC B-138, 4200 East Ninth Avenue, Denver, C0 80262. E-mail: Nicholas.Seeds@uchsc.edu.

Copyright $\odot 2003$ Society for Neuroscience $\quad$ 0270-6474/03/237368-08\$15.00/0
}

the mature brain, except for the cerebellum and the hippocampus, two regions associated with learning.

Several lines of evidence suggest that tPA is involved in CNS learning. tPA expression increases in the cerebellum of rats during operant conditioning of a complex motor task (Seeds et al., 1995). Overexpression of a tPA transgene enhances water maze performance (Madani et al., 1999). Similarly, long-term potentiation (LTP) induction in hippocampal slices (Qian et al., 1993) is associated with an increase in tPA expression, and inhibitors of tPA activity impair late-phase LTP in hippocampal slices (Baranes et al., 1998). Because the precise role tPA plays during learning is not known, we have investigated the involvement of tPA in the consolidation phase of learning in mice and the need for tPA gene expression and proteolytic activity during learning of a complex motor task, as assessed in tPA knock-out mice, and in the presence of specific tPA inhibitors.

\section{Materials and Methods}

Motor learning. All behavioral testing was done with adult (3-6 months of age) male C57BL/ 6 wild-type ( $\mathrm{tPA}+/+)$, heterozygote $(\mathrm{tPA}-/+)$, or tPA knock-out (tPA-/-) mice placed on a $>98 \%$ C57BL/6 background (Jackson Labs, Bar Harbor, ME). Mutant mice having different grandmothers were bred in our colony and back-crossed to wild-type controls every 10 generations to prevent strain divergence. Gene knock-outs were confirmed by the absence of tPA activity in zymography and amidolytic assays (Krystosek and Seeds, 1986). The mice were housed singly and given food ad libitum, but during training and testing were given limited access to water and maintained at $85-90 \%$ of their starting body weight. All animal protocols were approved by the Institutional Animal Care and Use Committee of our university. During motor learning, mice must learn to traverse a runway by placing their paws on the aluminum pegs that protrude horizontally from the walls of the runway; a task that is dependent on cerebellar function (Watson and McElligott, 1983; Bickford, 1993; Seeds et al., 1995). Initially, mice are shaped and trained on a regular (REG) peg pattern that conforms to their normal gait (Fig. 1). Water $(0.07 \mathrm{ml})$ is used to reinforce running across the apparatus, and water delivery is associated with a loud tone that serves as a signaling 


\section{A Regular peg pattern runway}

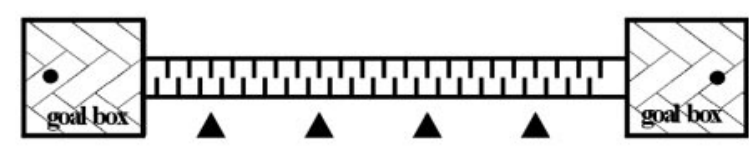

B Irregular peg pattern runway

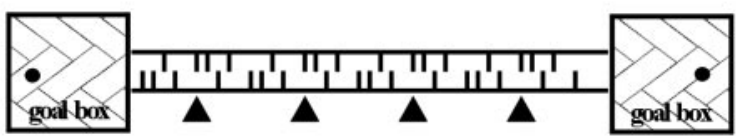

- water spout $\Delta$ photobeam detector

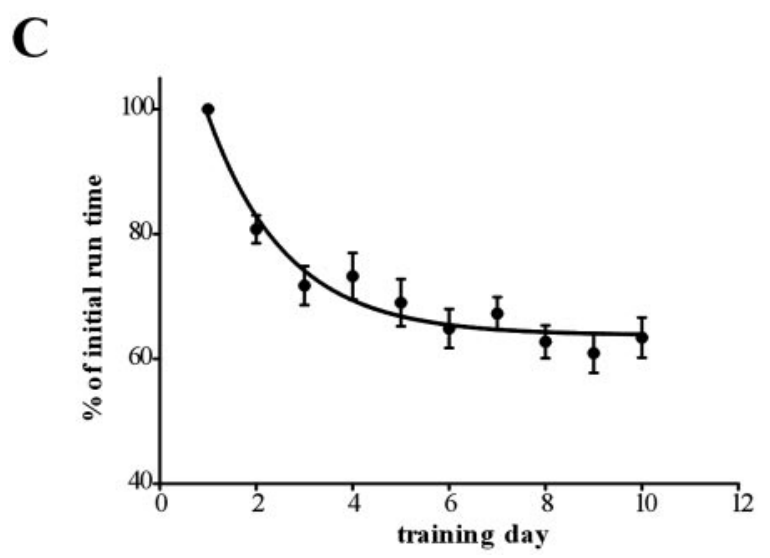

Figure 1. Motor learning curve and apparatus. Mice were trained on a complex motor task that involves learning to negotiate a runway consisting of aluminum pegs placed in a specific pattern, as depicted in the inset on the top right. Animals are shaped and trained with a water reward, delivered on the platform at each end of the runway, on the Regular pattern $(A)$, which closely matches their normal gait. After a 10-d interval, the animals are tested for their motor learning of the Irregular pattern $(B)$. Running times are expressed as a percentage of each mouse's initial runs on day $1(C)$. The majority of the improvement in running times (i.e., learning) takes place between days 1 and 2 .

stimulus and secondary reinforcer. Mice were water deprived overnight before training. Shaping of water drinking and running was achieved with the rods covered by sheets of cardboard. The mice were maintained under these conditions for several days until they were able to run successfully back and forth on the runway. After shaping of the runway performance, training proceeded by gradually removing pieces of the cardboard that covered the regular pegs. After shaping and training on the REG pattern, the mice were not exposed to the runway for 10-14 $\mathrm{d}$. The testing phase of the learning experiment consisted of daily sessions of 20 trials conducted on a novel irregular-spaced (IRR) pattern of pegs for 6-9 consecutive days. The average traverse time for each mouse was calculated daily; the percentage decrease from that mouse's average on day 1 was used as an index of the amount learned. Both the $t P A+/+$ and tPA $-/-$ mice showed runtimes on day 1 ranging from $8.3-16.1 \mathrm{sec}$, with average times of 11.1 and $10.9 \mathrm{sec}$, respectively. Similarly, there was no significant difference between the saline-infused and tPA inhibitorinfused groups for day 1 runtimes. Because each mouse's run time on day 1 was defined as $100 \%$, data from day 1 were not included in the statistical analysis. The percentage data from the subsequent days were normalized through a rank transformation and a two-way, repeated measures ANOVA performed on the data. Student's $t$ tests were used to directly compare learning between groups on each day of training.

In situ hybridization. Mice were trained as described and euthanized at specific times after training. The cerebella were rapidly removed and frozen, then embedded in O.C.T. (Miles, Elkhart, IN), and the paramedian lobule was cut in $16 \mu \mathrm{m}$ sections. Hippocampal tissue was removed from some of the same mice and similarly processed. The sections were fixed in 4\% paraformaldehyde-PBS for $15 \mathrm{~min}$, then processed for hybridization as described by Friedman and Seeds (1995) using the procedure of Simmons et al. (1989). The hybridization was performed with $5 \times 10^{6} \mathrm{cpm} / \mathrm{ml}$ of a 515 -base ${ }^{35} \mathrm{~S}$-cRNA (antisense or sense) riboprobe to part of the kringle 2 and the catalytic domains of mouse tPA in 50\% formamide at $62^{\circ} \mathrm{C}$ for $16 \mathrm{hr}$. Slides were processed through descending concentrations of $0.15 \mathrm{M} \mathrm{NaCl}, 30 \mathrm{~mm} \mathrm{Na}$ citrate (SSC), and a final wash in $0.1 \times \mathrm{SSC}$ at $65^{\circ} \mathrm{C}$ for $30 \mathrm{~min}$. The slides were dipped in Kodak NTB-2 emulsion and exposed 3 weeks, developed, and viewed by dark-field illumination. Pixel counting of digitized images of brain sections from the different experimental conditions, and at different exposure times, was used to quantify tPA mRNA with National Institutes of Health Image software. Multiple sections from three different mice were examined for each experimental condition.

Inhibition of protein synthesis. Protein synthesis was inhibited by anisomycin injection following the protocol of Squire and Davis (1975). Mice were given a subcutaneous injection of either saline or anisomycin $(150 \mathrm{mg} / \mathrm{kg}$ body weight) immediately before training on day 1 . Similarly, mice that had already learned the irregular peg running paradigm after $5 \mathrm{~d}$ of training were given similar injections before training on day 6 . Both sets of animals were tested for irregular peg walking on the following day.

Osmotic pumps. Forty-six C57BL/6 wild-type mice were implanted with osmotic pumps to deliver either artificial CSF (ACSF) $(n=22)$, plasminogen activator inhibitor type-1 (PAI-1) $(n=16)$, or tPA-STOP $(n=8)$ to the cerebellum during training on the IRR pegs (Alzet). Microosmotic pumps (100 $\mu$ l capacity; Direct Corp., Cupertino, CA) were filled with either ACSF (148 mM NaCl, $3.0 \mathrm{~mm} \mathrm{KCl}, 1.4 \mathrm{mM} \mathrm{CaCl}_{2}, 0.8 \mathrm{~mm}$ $\mathrm{MgCl}_{2}, 0.8 \mathrm{~mm} \mathrm{Na}_{2} \mathrm{HPO}_{4}$, and $0.2 \mathrm{~mm} \mathrm{NaH}{ }_{2} \mathrm{PO}_{4}$ ), PAI-1 (11.6 $\mu \mathrm{M}$; Calbiochem, La Jolla, CA), or tPA-STOP (1 mM; American Diagnostica, Greenwich, CT). The PAI-1 used for this study is a recombinant, mutant form that remains stable and active for an extended period $\left(\mathrm{t}_{1 / 2}=145 \mathrm{hr}\right.$ at $37^{\circ} \mathrm{C}$ ) (Berkenpas et al., 1995). Similarly, tPA-STOP was shown in amidolytic assays to be quite stable at $37^{\circ} \mathrm{C}$ for up to 2 weeks as a $1 \mathrm{~mm}$ solution (0.01 $\mu$ moles of tPA-STOP completely inhibited $160 \mathrm{IU}$ of tPA activity). All pumps were attached to $1.5 \mathrm{~cm}$ of ACSF-filled tubing and an infusion cannula (Alzet). The pumps were preincubated overnight in saline at $37^{\circ} \mathrm{C}$, allowing the pumps to begin to expel the ACSF initially present in the tubing and cannulae. On the day of surgery, mice were weighed and anesthetized with ketamine $\mathrm{HCl}(120 \mathrm{mg} / \mathrm{kg})$ and xylazine $\mathrm{HCl}(10 \mathrm{mg} / \mathrm{kg})$. A pump was placed in a mid-scapular, subcutaneous pocket, and the cannula was placed in a hole in the skull and cemented in place with cyanoacrolate such that the cannula protruded into the paramedian cerebellum. Each pump delivered $0.5 \mu \mathrm{l} / \mathrm{hr}$ for $\sim 7 \mathrm{~d}$. After surgery, mice were allowed to recover in their home cage, and the first day of training on the IRR pegs commenced $2 \mathrm{~d}$ after surgery. A second group of mice received pumps (ACSF, 12; PAI-1, 6; tPA-STOP, 7) after the fifth day of training on the IRR pegs. After surgery and recovery, training resumed for another $4 \mathrm{~d}$. At the end of each experiment, mice were sacrificed, and the brains were removed and examined to verify proper cannula placement. All osmotic pumps were empty at the time of sacrifice. All animal surgery and testing protocols were approved by our Institutional Animal Care and Use Committee.

Amidolytic assay. To determine the extent to which PA activity was inhibited in the cerebellum during PAI-1 infusions, we measured the PA inhibitory activity in the cerebellum 3, 7, and $10 \mathrm{~d}$ after pump implantation. Mice were implanted with either ACSF- or PAI-1-filled pumps as described previously. After 3 (ACSF, $n=3$; PAI-1, $n=3$ ), 7 (ACSF, $n=$ 2; PAI- $1, n=4$ ), or 10 (ACSF, $n=2$; PAI- $1, n=2$ ) days, the cerebella were removed and homogenized in buffer Z (1:4 w/v; $0.05 \mathrm{M}$ Tris, 0.15 mм NaCl, 0.16 mm EDTA, and 1\% Tween 80 ) with $1.5 \%$ SDS. Samples were spun at 15,000 rpm for $5 \mathrm{~min}$, and the soluble fraction was heated to $37^{\circ} \mathrm{C}$ for $30 \mathrm{~min}$. Twenty microliters of the soluble fraction were then incubated at $37^{\circ} \mathrm{C}$ with recombinant tPA (Genentech, San Francisco, CA), a plasmin-sensitive chromogenic substrate (S2251; $1.6 \mu \mathrm{M}$; American Diagnostica), $2.5 \mu \mathrm{g}$ of high molecular weight poly-D-lysine, and 
Table 1. Cerebellar complex motor learning requires new protein synthesis

\begin{tabular}{llc}
\hline Condition & Day & Irregular peg running time \\
\hline None & 1 & $100 \%$ \\
Saline injection (day 1) & 2 & $77 \%( \pm 5.7 \%)$ \\
Anisomycin injection (day 1) & 2 & $100 \%( \pm 3.5 \%)^{*}$ \\
Saline-injected/uninjected mice & 6 & $68 \%( \pm 6 \%)$ \\
Saline injections (day 6) & 7 & $65 \%( \pm 3 \%)$ \\
Anisomycin injection (day 6) & 7 & $64 \%( \pm 6 \%)$ \\
\hline
\end{tabular}

Because the greatest increase in learning occurs between the first and second learning sessions, i.e., days 1 and 2 , mice received a subcutaneous injection of saline or the protein synthesis inhibitor anisomycin $(150 \mathrm{mg} / \mathrm{kg})$ immediately before training on day 1 . Furthermore, mice that had already learned the irregular peg running paradigm by day 6 were given similar injections. Inhibiting protein synthesis on day 1 blocks motor learning, whereas inhibiting protein synthesis on day 6 has no effect on peg running performance.

*Significantly different from saline injection, $p<0.01$

$.0625 \mathrm{U}$ of plasminogen. The ability of tPA to convert plasminogen to plasmin was monitored by measuring the absorbance at $405 \mu \mathrm{M}$ wavelength every 2 min for 80 min with a Bio-Tek (Winooski, VT) microplate reader. By comparing the results with those from a simultaneously processed standard curve with known amounts of tPA activity, the amount of inhibition of tPA activity in the cerebellar samples was determined. Student's $t$ tests comparing ACSF- and PAI-1-infused groups were performed for each time point. Amidolytic assays were also used to confirm the tPA inhibitory activity of tPA-STOP and the stability of this activity at $37^{\circ} \mathrm{C}$.

\section{Results}

To investigate the involvement of $\mathrm{PA}$ in the consolidation phase of learning in mice, we used a complex motor task of irregular peg walking to receive a water reward. A previously described (Watson and McElligott, 1983; Seeds et al., 1995) apparatus for rats was modified to accommodate mice in a narrower $(4 \mathrm{~cm}$ wide) runway with more closely spaced pegs, which matched the mouse's normal gait. Initially, the mice were shaped and trained on a REG peg pattern (Fig. $1 A$ ). After remaining in their home cage for 2 weeks, the mice were again placed in the runaway; however, the pegs were now in an IRR pattern (Fig. $1 B$ ). The average running time for each mouse was compared with its average speed for the 20 trials on day 1 . The mice readily learned to navigate this novel peg pattern, as indicated by their improved running times on days $1-5$ of training (Fig. 1C); after this time the curve becomes asymptotic. As with many learning paradigms, the greatest improvement (i.e., learning) was seen between testing day 1 and day 2 (Fig. 1C). The critical nature of this time window for consolidation of learning was confirmed by its dependence on new protein synthesis as shown in Table 1 . Mice receiving a saline injection before training on day 1 show a $23 \%$ improvement in running times on the irregular pegs on day 2; however, those mice receiving an injection of the protein synthesis inhibitor anisomycin showed no improvement (i.e., learning) during training on day 2. To demonstrate that the anisomycin effect was on motor learning and not on peg running performance, mice that already learned the irregular peg running paradigm by day 6 were given similar injections on day 6 , and there was no dif- ference between the running performance of saline- or anisomycin-injected mice when tested on day 7.

Thus, mouse cerebella were examined during this active phase of learning for the expression of tPA mRNA. Cerebella were collected from mice at various times after training on day 1 and rapidly frozen. Fresh frozen sections were processed for in situ hybridization with a radiolabeled antisense cRNA probe to mouse tPA mRNA. The localization of tPA mRNA was visualized by dark-field illumination microscopy. Induction of tPA mRNA expression in mouse cerebellar granule neurons was quite dramatic within $0.5-1 \mathrm{hr}$ after training on day 1 (Figs. $2 A, 3$ ), when compared with cerebellar sections of motor activity control mice that were simply exercised by freely running over covered-pegs (Fig. $2 C$ ), or untrained naive mice (data not shown). Sense cRNA probes failed to show specific binding to the cerebellar tissue. The induction of tPA mRNA appears restricted to the granule neuron layer and is noticeably absent from Purkinje neurons in mice, which is in distinct contrast to what we described in rats (Seeds et al., 1995). In rats, there was a dramatic induction of tPA mRNA in cerebellar Purkinje neurons and to a lesser extent in granule neurons. Furthermore, in contrast to other studies in rats (Ware et al., 1995), we have not seen tPA mRNA expression in mouse Purkinje neurons at any developmental stage examined (Friedman and Seeds, 1994, 1995). This is most probably because of mouse and human tPA genes lacking the cAMP-responsive element used by the rat tPA gene and having a phorbol ester-responsive AP-1 site at this same position (Rickles et al., 1989; Feng et al., 1990). However, cAMP can promote tPA expression in some mouse cells (Holmberg et al., 1995).

Because tPA appears to be an immediate early gene and is under the influence of an AP-1 promoter in mice (Rickles et al., 1989), it was important to rule out the possibility that this tPA induction was mediated by stress-related increases in c-fos (Ryabinin et al., 1995), a known activator of AP-1 sites (Holmberg et al., 1995). Stress-control mice were allowed to walk out onto the
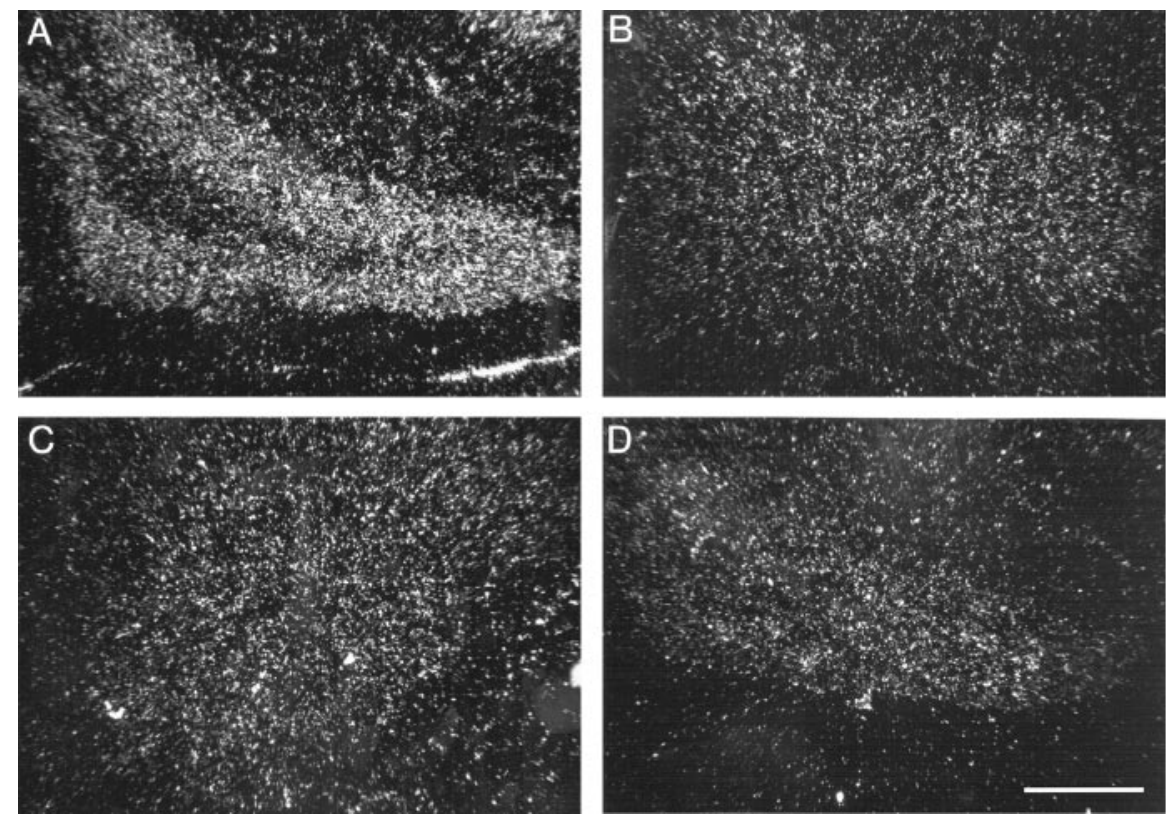

Figure 2. $\quad$ tPA mRNA induction in cerebellar granule neurons during motor learning. tPA mRNA is rapidly induced in mouse cerebellar granule neurons as seen by in situ hybridization on a tissue section taken $1 \mathrm{hr}$ after training $(A)$ on the irregular peg pattern on day 1 with dark-field microscopy of folia V. Mice subjected to stress $(B)$, by being confined and having to cling to the pegs for 30 min, show background levels of tPA mRNA similar to untrained naive mice, or mice exercised $(C$ ) by repetitive running over covered pegs. Mice that have already learned the task by day 6 also show a very low level of tPA mRNA expression from simply performing $(D)$ this task as seen $1 \mathrm{hr}$ after running on the irregular pegs on day 6. Scale bar (in $D), 250 \mu \mathrm{m}$. 


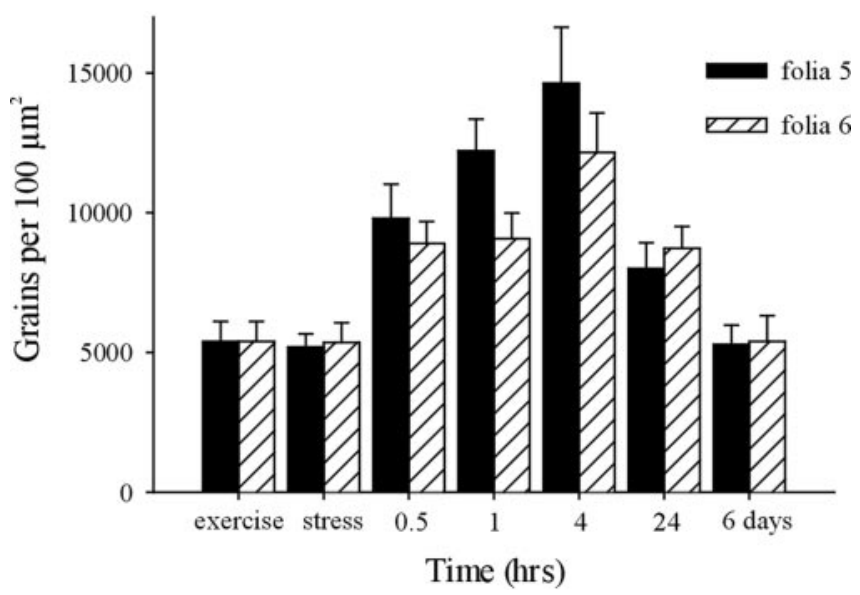

Figure 3. TPA mRNA induction during complex motor learning as quantified by ${ }^{35} \mathrm{~S}$ antisense cRNA probe binding to cerebellar sections from mice at various times $(0.5,1,4$, and 24 hr) after training on day 1 , or at $1 \mathrm{hr}$ after training on day 6 , or mice subjected to conditions of simple exercise or stress and sampled $1 \mathrm{hr}$ later. TPA mRNA induction is seen as early as $30 \mathrm{~min}$ after the training session on day 1, and tPA mRNA increases threefold by $4 \mathrm{hr}$ after training. Exercised, stressed, and learned mice all show background levels of tPA mRNA similar to those seen in naive mice. Thus, tPA mRNA is rapidly induced in cerebellar granule neurons during the early stages of learning and is distinct from exercise, stress, or a simple performance response.

irregular pegs, and then their path was blocked both in front and behind, such that they were confined and had to hold onto the pegs for the entire $30 \mathrm{~min}$. session to prevent their falling through the runway. Similar to the exercised controls (Fig. 2C), the stressed-mice did not show an increase in cerebellar tPA mRNA expression (Fig. 2 B). Furthermore, this induction of tPA mRNA is not simply related to motor performance, because mice that have already learned the complex motor task by training day 6 also show a very low level of tPA mRNA expression from simply performing this task, as seen $1 \mathrm{hr}$ after running on the irregular pegs on day 6 (Fig. $2 D$ ).

The tPA mRNA levels in the granule neuron layer of these mice (Fig. 2) $1 \mathrm{hr}$ after training, as well as tPA mRNA levels from cerebella taken at various times after the training session, have been quantified. Figure 3 shows the mean grain density of the tPA cRNA probe binding to these different cerebellar sections. tPA mRNA induction is rapid, with significant levels being seen as early as $0.5 \mathrm{hr}$ after training on day 1. tPA mRNA expression increases threefold, reaching maximal levels by $4 \mathrm{hr}$ after training on day 1 , and then declines.

The induction of tPA mRNA after motor learning is specific for the cerebellum. Although tPA mRNA is readily detectable in the mouse hippocampus, there is no significant increase in tPA mRNA levels in the CA1, CA3, or dentate gyrus regions of the hippocampus at $1 \mathrm{hr}$ (or $4 \mathrm{hr}$ ) after complex motor learning, when compared with the exercised control mice (Fig. 4).

The dependence of cerebellar motor learning on the presence of tPA was assessed using mice lacking both copies of the tPA gene. These tPA-/- knock-out mice were maintained on a $>98 \%$ C57BL/6 genetic background. tPA knock-out mice were compared with tPA heterozygotes and to wild-type mice for their ability to learn the irregular peg walking paradigm. The irregular peg performance of tPA heterozygotes did not differ from wild-type mice, so both groups were pooled as controls in Figure 5. Knock-out mice missing both tPA genes show impaired motor learning with a significant (two-way ANOVA; $p<0.03$ ) reduction in both their rate and extent ( $28 \%$ decrease) of learning compared with their heterozygous and normal littermate controls.

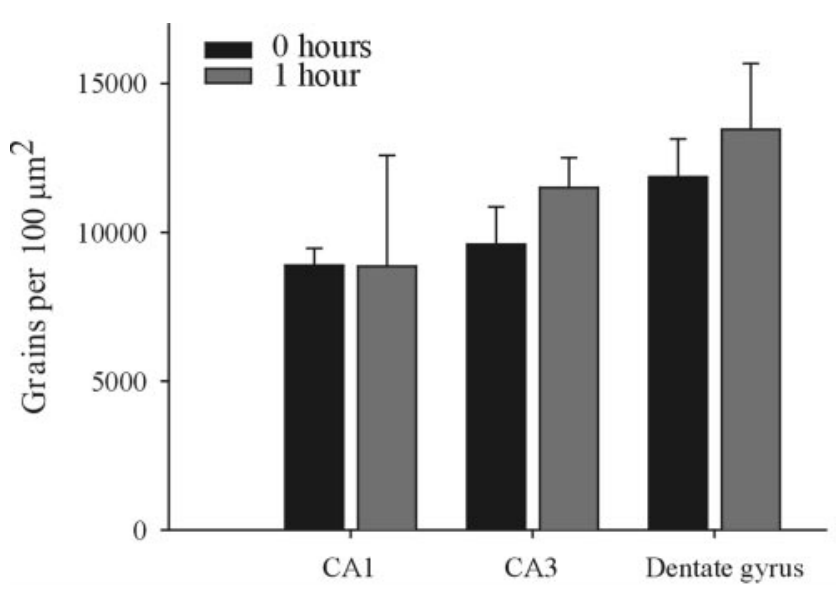

Figure 4. No induction of tPA mRNA expression in the mouse hippocampus during irregular peg running. The CA1, CA3, and dentate gyrus regions of the hippocampus show no significant induction $\mathrm{PPA}$ mRNA at $1 \mathrm{hr}$ after the complex motor learning paradigm.

To test whether the proteolytic activity of tPA was necessary for motor learning, specific inhibitors of tPA were infused into the cerebellum via micro-osmotic pumps during motor learning. These micropumps deliver $\sim 0.5 \mu \mathrm{l} / \mathrm{hr}$ for $\sim 7 \mathrm{~d}$. The effectiveness of infused PAI-1 to inhibit endogenous cerebellar tPA activity was assessed in cerebellar homogenates as compared with mice infused with ACSF. Table 2 shows that tPA activity of homogenates of cerebella infused with PAI- 1 and prepared on day 2 of training (i.e., $3 \mathrm{~d}$ after pump implantation) was significantly inhibited 78\% $(t=-7.468 ; p=0.002)$ as compared with tPA activity in those cerebella receiving ACSF. Homogenates prepared on training day 6 or day 9, after the pumps are empty, showed no significant differences and lacked any inhibitory activity. The use of ${ }^{125}$ I-PAI- 1 to monitor its diffusion showed that PAI-1 diffusion was restricted to the cerebellum, was heavily distributed within a $1.5 \mathrm{~mm}$ radius, and was seen at a maximal radius of $4.5 \mathrm{~mm}$ from the cannula site; thus, covering $>90 \%$ of the $0.9-1-\mathrm{cm}$-wide mouse cerebellum.

A group of mice were shaped and trained on the REG peg pattern for $5 \mathrm{~d}$ until their running times became asymptotic. After a 2 week interval, the mice were implanted with micro-osmotic pumps containing either ACSF or PAI-1. Cerebellar infusions of PAI-1 impaired learning of the IRR peg pattern compared with ACSF infusions. Mice in which PAI-1 was infused into the cerebellum showed an overall smaller percentage decrease in run times than mice receiving ACSF infusions (two-way, repeated measures ANOVA; $p=0.042$; Fig. $6 A$ ). Mice receiving ACSF infusions had a $27 \%$ reduction in average traverse time on the second day of training. In contrast, mice receiving PAI-1 infusions had only a $12 \%$ decrease in average traverse time on day 2 . Notably, PAI-1-infused mice showed significantly less learning than ACSF-infused mice after training on day $1(t=-2.0 ; \mathrm{df}=$ $30 ; p=0.05)$, when the majority of learning occurs and when tPA mRNA expression in the cerebellum is highest.

PAI-1 infusions did not decrease the activity level of the mice, and no differences were observed between groups in the mice's motivation to perform the motor task. All mice, regardless of treatment would immediately drink the water reward after each successful crossing, indicating similar levels of motivation, and all mice consumed similar amounts of water during the daily posttraining ad libitum access. Importantly, the groups did not differ in the average number of crossings per day (data not shown); the 
PAI-1-infused mice just ran slower; so all mice had a similar amount of experience on the irregular peg pattern.

Pump implantation and subsequent infusion of either ACSF or PAI-1 did not impair the mice's ability to perform a previously learned motor task. Mice that had been trained on the irregular peg pattern for $5 \mathrm{~d}$ and that had shown no significant decrease in traverse times after the fourth training day were implanted with either ACSF- or PAI-1-filled pumps. Subsequent training on the irregular peg pattern showed no significant differences in performance between groups and no significant increase in average run time when compared with day 4 and day 5 run times (Fig. 6B).

Because PAI-1 is a large molecule and forms a $115 \mathrm{kDa}$ complex with $\mathrm{tPA}$, it was important to see whether a small, active site-specific tripeptide inhibitor would also inhibit motor learning. Similar to the results with PAI-1, infusion of the small $400 M_{\mathrm{r}}$ tPA-STOP into the cerebellum inhibits tPA activity and impairs motor learning. Mice implanted with cerebellumdirected pumps filled with $1 \mathrm{~mm}$ tPA-STOP showed significantly impaired motor learning compared with mice receiving ACSFfilled pumps (two-way, repeated measures ANOVA; $p=.007$; Fig. 7A). As seen with the PAI-1 infusions, tPA-STOP did not impair the mice's ability to perform a previously learned task (Fig. $7 B$ ).

\section{Discussion}

These studies have shown that learning to negotiate a complex motor task leads to a rapid and dramatic induction of tPA mRNA in cerebellar granule neurons of mice. Induction of the extracellular protease tPA occurs during the critical consolidation phase of learning. Most importantly, tPA appears to play a necessary role in learning, because mice without the tPA genes show significantly impaired motor learning, as did mice whose cerebellar tPA activity was inhibited. These findings support the hypothesis that tPA may have a fundamental role in synaptic remodeling associated with synaptic plasticity.

With complex motor learning paradigms, it is important to distinguish those events that are simply related to performing the motor task from those events that reflect the learning associated with the motor task. Many of the rodent learning tasks, either spatial or motor, show similar learning curves over a period of a few days, where the greatest learning or improvement occurs after the first or second day of trials. Consolidation of learning, which requires new gene expression and protein synthesis, occurs during this critical time window. However, those events related to just performing the task are reproduced with each trial. When the learning curves become asymptotic, the mice have learned the task. Therefore, in contrast to gene activities expressed early in the trials that may be part of the learning process, those gene activities expressed after the task is mastered primarily reflect performance. In trained mice, simply performing the motor task of irregular peg walking after $6 \mathrm{~d}$ of trials does not induce tPA gene expression (Fig. 2D); however, in those mice in the process of learning to navigate the irregular pegs, training does induce tPA gene expression (Fig. 2A). Furthermore, this induction of
tPA gene expression was independent of induced stress or physical exercise (Fig. $2 B, C$ ).

The requirement for tPA gene expression during motor learning, as demonstrated here by the impaired motor learning in tPA knock-out mice, is in agreement with two other studies showing abnormal late-phase hippocampal LTP (Frey et al., 1996) and poor performance on two-way active avoidance, a striataldependent task (Huang et al., 1996), in tPA knock-out mice on a heterogeneous (C57BL/SV129) genetic background. Additional support for a role for tPA expression in learning is seen in the enhanced performance in the Morris water maze and the homing holeboard tasks by mice overexpressing the tPA gene (Madani et al., 1999).

Surprisingly, learning deficits in PAI-1- or tPA-STOP-infused mice persist throughout the $9 \mathrm{~d}$ of training despite the fact that, by training day 6 , the pumps are exhausted and inhibition levels have dropped to baseline, ACSF-infused levels. This finding may reflect the time course over which $\mathrm{tPA}$ effects motor learning. The majority of improvement in traverse time occurs during the first $2 \mathrm{~d}$ of training, and no significant reductions in traverse time are seen after the fourth day of training. Similarly, training during days 1 and 2 elicits significant increases in tPA expression in the cerebellum; by training day 6 , tPA mRNA remains at baseline levels after training. Therefore, inhibition of tPA activity during the initial period of motor training, when tPA expression is elevated, leads to impaired performance of the motor task that persists both in the absence of increased tPA expression and in the absence of inhibition of tPA activity when the pumps run out. This finding is consistent with a model in which only the initial stage of motor learning involves tPA activity and is, therefore, sensitive to inhibition of PA. One possibility is that sensory signals from missteps on the pegs elicit increases in tPA mRNA expression in the cerebellum and that this increased tPA expression is permissive of motor learning. After several training days, the number of missteps may decline to the point where increased tPA expression is no longer elicited and motor learning is less probable.

Although inhibition of plasminogen activator activity impairs motor learning, these treatments did not prevent improvement 
Table 2. Inhibition of tPA activity in cerebellar homogenates after infusions of either PAI- 1 or ACSF

\begin{tabular}{lllr}
\hline & \multicolumn{2}{l}{ tPA activity remaining } & \\
\cline { 2 - 4 } & Training day 2 & Training day 6 & Training day 9 \\
\hline PAI-1 infused & $0.48 \pm 0.2 \mathrm{IU}$ & $2.67 \pm 0.3 \mathrm{IU}$ & $3.0 \pm 0.4 \mathrm{IU}$ \\
ACSF infused & $2.15 \pm 0.1 \mathrm{IU}$ & $2.38 \pm 0.3 \mathrm{IU}$ & $2.15 \pm 0.6 \mathrm{IU}$ \\
\hline
\end{tabular}

${ }^{a}$ Significantly different from ACSF infused, $p<0.01$.
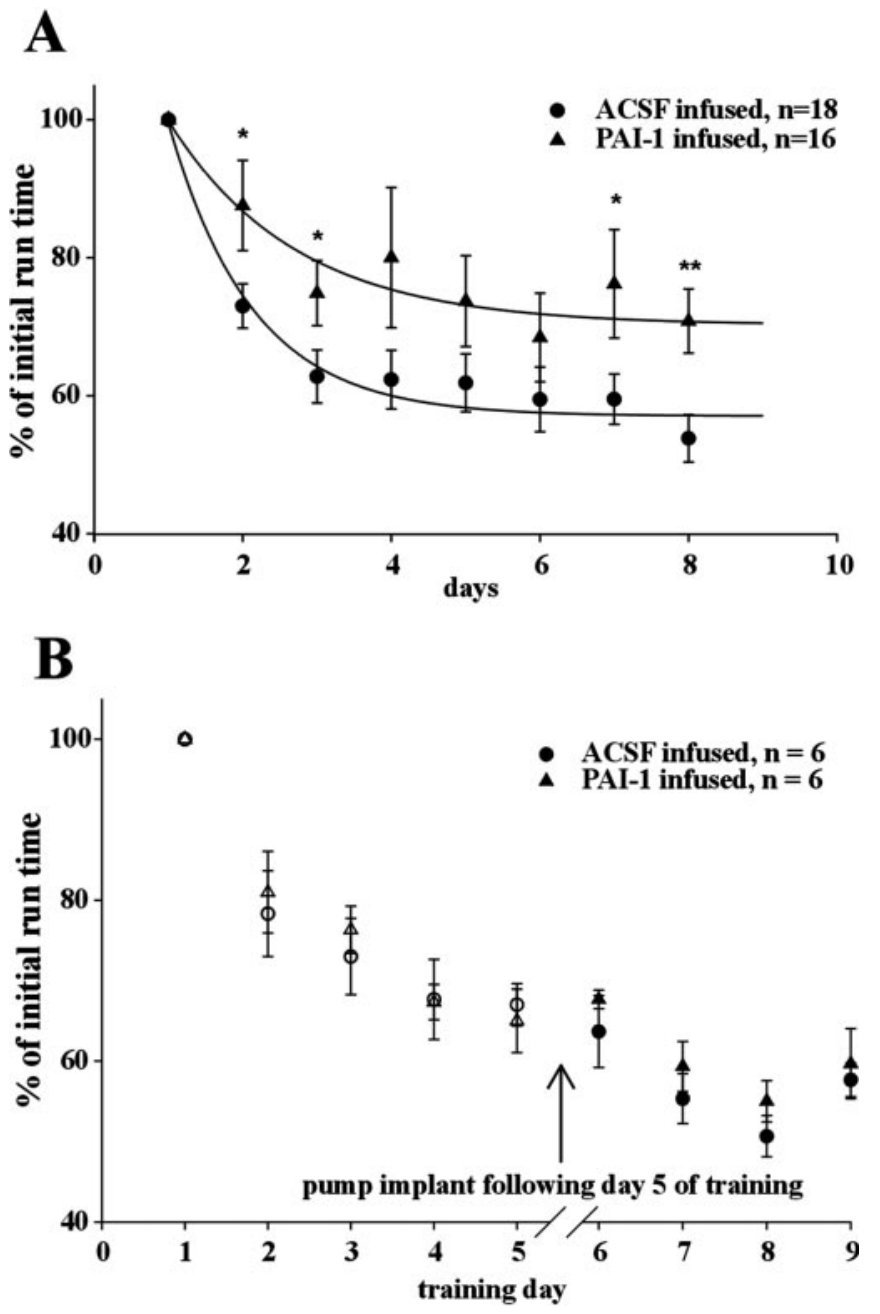

Figure 6. Intracerebellar infusions of PAl-1 impaired motor learning but not performance of a previously learned motor task. $A$, Mice that received continuous intracerebellar infusions of PAl-1 showed significantly less learning than those receiving ACSF infusions (two-way, repeated measures ANOVA; $p=0.042$ ). Error bars represent SEM. *Days in which the average percentage decrease from initial run time was significantly different between the two groups $(p \leq 0.05) ;{ }^{* *} p<0.01$. B, All mice were initially trained on an IRR peg pattern (open symbols). After $5 \mathrm{~d}$ of training, mice were implanted with cerebellum-directed pumps filled with either PAI-1 or ACSF. After pump implantation, mice in both groups (solid symbols) continued to perform the motor task at levels similar to those before surgery.

on the motor learning task. Some of this residual learning could be because of residual tPA activity. Although cerebellum homogenates from PAI-1-implanted mice show extensive inhibition of tPA on the second day of training, there may not be a complete block of endogenous tPA activity. Alternatively, some aspects of motor learning may not require tPA, as indicated in the tPA knock-out mouse (Fig. 5). These results are similar to hippocampal LTP, in which inhibiting tPA activity or knocking out the tPA gene attenuates, but does not abolish, late-phase LTP (Baranes et al., 1998).
The acquisition of complex motor skill is associated with increased cerebellar activity and structural remodeling of synapses in the cerebellar cortex (Black et al., 1990; Steitz and Roland, 1992). There is a quantitative increase in the number of granule neuron parallel fiber synapses on Purkinje cell dendrites in the cerebellar cortex during complex motor learning that is not seen with simple motor activity (Kleim et al., 1998a). Although the deep cerebellar nuclei are implicated in the acquisition of motor skills (Lavond and Steinmetz, 1989), there is no readily apparent structural plasticity in this region (Kleim et al., 1998b). Furthermore, Hesslow et al. (1999) have shown that motor input via mossy fibers onto cerebellar granule neurons leads to memory storage in the cerebellar cortex during motor learning. Similarly, Attwell et al. (2002) have shown that motor memory consolidation is mediated by the cerebellar cortex. Thus, synaptic remodeling of a qualitative and quantitative nature in the cerebellar cortex is associated with complex motor learning.

The finding that motor learning involves tPA is consistent with a model in which motor learning consists, in part, of persistent changes in the strength of connections among neurons in the cerebellum. Motor learning causes an increase in tPA mRNA within the cerebellar granule cell layer, in which in-coming mossy fibers synapse on granule cells. Granule cell bodies in the granule layer extend axons that give rise to parallel fibers that synapse on Purkinje cell dendrites and dendrites of inhibitory interneurons in the molecular layer. LTP has been demonstrated at the mossy fiber-granule cell synapse, and both LTP and long-term depression (LTD) have been demonstrated at the parallel fiber-Purkinje cell synapse (Ito et al., 1982; Salin et al., 1996; D'Angelo et al., 1999). These long-lasting excitability changes develop in the cerebellum over a period of $2 \mathrm{hr}$ after the induction stimulus (Jorntell and Ekerot, 2002). Although it is not known whether cerebellar LTP requires tPA activity, these findings suggest a role for tPA in the cerebellum that is similar to the role tPA may play in the hippocampus. That is, motor learning may involve LTP (and LTD) at mossy fiber-granule cell and/or parallel fiber-Purkinje cell synapses, and loss of tPA activity may impair learning by impairing LTP/LTD.

Induced expression of tPA mRNA and protein (Seeds et al., 1995 ) in the cerebellum of mice and rats occurs within the first 4 $\mathrm{hr}$ after initial training for a complex motor learning paradigm. Importantly, this time frame coincides closely with the consolidation phase of working memory, the $\sim 5 \mathrm{hr}$ time window required before a motor skill can be learned and retained for the long term, before being tested on a conflicting second motor task (Shadmehr and Brashers-Krug, 1997).

In fact, tPA may play a general role in facilitating structural changes related to synaptic plasticity. In the hippocampus, LTP leads to synaptogenesis (Engert and Bonhoeffer, 1999; Toni et al., 1999) and involves increases in tPA expression. In the visual cortex, reverse occlusion-induced plasticity that involves synaptogenesis is sensitive to tPA inhibitors, whereas plasticity that involves the loss of connections without synaptogenesis is not sensitive to tPA inhibitors (Müller and Griesinger, 1998). In the cerebellum, motor learning leads to an increase in the number of synapses per Purkinje cell (Black et al., 1990) and, as shown here, induces tPA expression, and inhibition of tPA activity in the cerebellum impairs motor learning. The increasing number of examples of an association between tPA and synaptogenesis suggests that tPA may be part of a common mechanism for activitydependent structural remodeling.

Synaptic plasticity associated with learning may include the modification of neuronal receptors, the formation of new synap- 

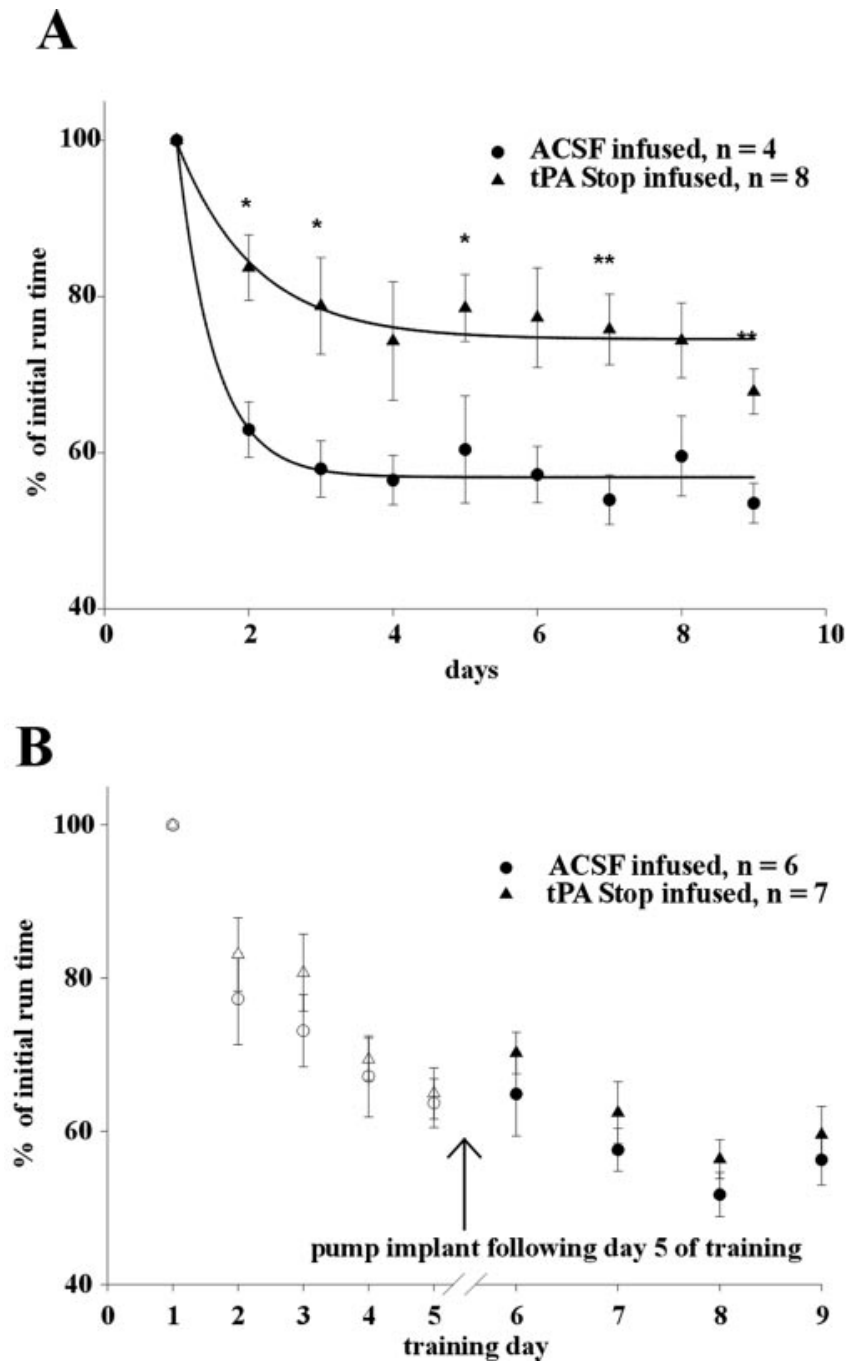

Figure 7. Intracerebellar infusions of TPA-STOP impaired motor learning but not performance of a previously learned motor task. A, Mice that received continuous intracerebellar infusions of TPA-STOP showed significantly less learning than those receiving ACSF infusions (two-way, repeated measures ANOVA; $p=0.007$ ). Error bars representSEM. *Days in which the average percentage decrease from initial run time was significantly different between the two groups $(p<0.05)$. ${ }^{* *} p<0.01 \ln B$, All mice were initially trained on an IRR peg pattern (open symbols). After $5 \mathrm{~d}$ of training, mice were implanted with cerebellum-directed pumps filled with either IPA-STOP or ACSF. After pump implantation, mice in both groups (solid symbols) continued to perform the motor task at levels similar to those before surgery.

tic sites, as well as the expansion of the synaptic active zone on preformed synapses. The participation of tPA in various forms of tissue remodeling throughout the body make it a likely candidate molecule for synaptic remodeling during learning. tPA may act directly to cleave and activate substrates, including the NMDA-R1 receptor subunit (Nicole et al., 2001) and the latent neurotrophic growth factor HGF/SF (Mars et al., 1993; Thewke and Seeds, 1996), or its more notable substrate, plasminogen, which is expressed in both the adult cerebellum (Basham and Seeds, 2001) and hippocampus (Tsirka et al., 1997). Neuronal secreted tPA bound to the neuronal surface or extracellular matrix would locally activate plasminogen; the widely active plasmin may digest cell-cell and cell-matrix adhesions, cell surface receptors, or expose cryptic sites for synaptogenesis. Thus, tPA may facilitate synaptic plasticity during motor learning by synapse activation or initiating structural changes and synaptic remodeling.

\section{References}

Attwell PJ, Cooke SF, Yeo CH (2002) Cerebellar function in consolidation of a motor memory. Neuron 34:1011-1020.

Bailey CH, Kandel ER (1993) Structural changes accompanying memory storage. Annu Rev Physiol 55:397-426.

Baranes D, Lederfein D, Huang Y-Y, Chen M, Bailey CH, Kandel ER (1998) Tissue plasminogen activator contributes to the late phase of LTP and to synaptic growth in the hippocampal mossy fiber pathway. Neuron 21:813-825.

Basham ME, Seeds NW (2001) Plasminogen expression in the neonatal and adult mouse brain. J Neurochem 77:318-325.

Berkenpas MB, Lawrence DA, Ginsburg D (1995) Molecular evolution of plasminogen activator inhibitor-1 functional stability. EMBO J 14:2969-2977.

Bickford P (1993) Motor learning deficits in aged rats are correlated with loss of cerebellar noradrenergic function. Brain Res 620:133-138.

Black JE, Isaacs KR, Anderson BJ, Alcantara AA, Greenough WT (1990) Learning causes synaptogenesis, whereas motor activity causes angiogenesis, in cerebellar cortex of adult rats. Proc Natl Acad Sci USA 87:5568-5572.

D'Angelo E, Rossi P, Armano S, Taglietti V (1999) Evidence for NMDA and mGlu receptor-dependent long-term potentiation of mossy fiber-granule cell transmission in rat cerebellum. J Neurophysiol 81:277-287.

Dano K, Andreasen P, Grondhal-Hansen J, Kristensen P, Neilsen P (1985) Plasminogen activators, tissue degradation and cancer. Adv Cancer Res 44:139-166.

Engert F, Bonhoeffer T (1999) Dendritic spine changes associated with hippocampal long-term synaptic plasticity. Nature 399:66-70.

Feng P, Ohlsson M, Ny T (1990) The structure of the TATA-less rat tissue plasminongen activator gene. Species specific divergences in the promoter predict differences in regulation of gene expression. J Biol Chem 265:2022-2027.

Frey U, Muller M, Kuhl D (1996) A different form of long-lasting potentiation revealed in tissue plasminogen activator mutant mice. J Neurosci 16:2057-2063.

Friedman GC, Seeds NW (1994) Tissue plasminogen activator expression in the embryonic nervous system. Brain Res Dev Brain Res 81:41-49.

Friedman GC, Seeds NW (1995) Tissue plasminogen activator mRNA expression in granule neurons coincides with their migration in the developing cerebellum. J Comp Neurol 360:658-670.

Hesslow G, Svensson P, Ivarsson M (1999) Learned movements elicited by direct stimulation of cerebellar mossy fiber afferents. Neuron 24:179-185.

Holmberg M, Leonardsson G, Ny T (1995) The species-specific differences in the cAMP regulation of the tissue plasminogen activator gene between rat, mouse and human is caused by a one-nucleotide substitution in the cAMPresponsive element of the promoters. Eur J Biochem 231:466-474.

Huang Y-Y, Bach ME, Lipp H-P, et al (1996) Mice lacking the gene encoding tissue-type plasminogen activator show a selective interference with late-phase long-term potentiation in both Schaffer collateral and mossy fiber pathways. Proc Natl Acad Sci USA 93:8699-8704.

Ito M, Sakurai M, Tongroach P (1982) Climbing fibre induced depression of both mossy fibre responsiveness and glutamate sensitivity of cerebellar Purkinje cells. J Physiol 324:113-134.

Jorntell H, Ekerot C-F (2002) Reciprocal bidirectional plasticity of parallel fiber receptive fields in cerebellar Purkinje cells and their afferent interneurons. Neuron 34:797-806.

Kleim JA, Armstrong K, Napper R, Jones T, Greenough WT (1998a) Selective synaptic plasticity within the cerebellar cortex following complex motor skill learning. Neurobiol Learn Mem 69:274-289.

Kleim JA, Pipertone M, Czerlonis C, Greenough WT (1998b) Structural stability within the lateral cerebellar nucleus of the rat following complex motor learning. Neurobiol Learn Mem 69:290-306.

Krystosek A, Seeds NW (1981) Plasminogen activator secretion by granule neurons in cultures of developing cerebellum. Proc Natl Acad Sci USA 78:7810-7812.

Krystosek A, Seeds NW (1986) Normal and malignant cells including neurons deposit plasminogen activator on the growth substratum. Exp Cell Res 166:31-46.

Lavond DG, Steinmetz JE (1989) Acquisition of classical conditioning without cerebellar cortex. Behav Brain Res 33:113-164.

McGuire PG, Seeds NW (1990) Degradation of underlying extracellular matrix by sensory neurons during neurite outgrowth. Neuron 4:633-642.

Madani R, Hulo S, Toni N, Madani H, Steimer T, Muller D, Vassalli J-D 
(1999) Enhanced hippocampal long-term potentiation and learning by increased neuronal expression of tissue-type plasminogen activator in transgenic mice. EMBO J 18:3007-3012.

Mars WM, Zarnegar R, Michalopoulos GK (1993) Activation of hepatocyte growth factor by the plasminogen activators uPA and tPA. Am J Pathol 143:949-958.

Müller CM, Griesinger CB (1998) Tissue plasminogen activator mediates reverse occlusion plasticity in visual cortex. Nat Neurosci 1:47-53.

Nicole O, Docagne F, Ali C, Margaill I, Carmeliet P, Mackenzie ET, Vivien D, Buisson A (2001) The proteolytic activity of tissue plasminogen activator enhances NMDA receptor-mediated signaling. Nat Med 7:59-64.

Pittman RN, Ivins J, Buettner H (1989) Neuronal plasminogen activators: cell surface binding sites and involvement in neurite outgrowth. J Neurosci 9:4269-4286.

Qian Z, Gilbert ME, Colicos MA, KandelER, KuhlD (1993) Tissue plasminogen activator is induced as an immediate-early gene during seizure, kindling and long-term potentiation. Nature 361:453-456.

Rickles RJ, Darrow A, Strickland S (1989) Differentiation-responsive elements in the $5^{\prime}$ region of the mouse tPA gene confer two-stage regulation by retinoic acid and cAMP in teratocarcinoma cells. Mol Cell Biol 9:1691-1704.

Ryabinin AE, Melia K, Cole M, Bloom F, Wilson M (1995) Alcohol selectivity attenuates stress induced c-fos expression in rat hippocampus. J Neurosci $15: 721-730$.

Saksela O, Rifkin D (1988) Cell associated plasminogen activation: regulation and physiological function. Annu Rev Cell Biol 4:93-126.

Salin PA, Malenka R, Nicoll R (1996) Cyclic AMP mediates a presynaptic form of LTP at cerebellar parallel fiber synapses. Neuron 16:797-803.

Seeds NW, Basham ME, Haffke SC (1999) Neuronal migration is retarded in mice lacking the tissue plasminogen activator gene. Proc Natl Acad Sci USA 96:14118-14123.

Seeds NW, Williams BL, Bickford PC (1995) Tissue plasminogen activator induction in Purkinje neurons after cerebellar motor learning. Science 270:1992-1994.

Shadmehr R, Brashers-Krug T (1997) Functional stages in the formation of human long-term motor memory. J Neurosci 17:409-419.

Simmons DM, Arriza J, Swanson L (1989) A complete protocol for in situ hybridization of mRNAs in brain and other tissues with radiolabeled single-stranded RNA probes. J Histotech 12:169-181.

Squire LR, Davis HP (1975) Cerebral protein synthesis inhibition and discrimination training. Behav Biol 13:49-57.

Steitz RJ, Roland PE (1992) Learning of sequential finger movements in man: combined kinematic and PET study. Eur J Neurosci 4:154-165.

Thewke DP, Seeds NW (1996) Expression of hepatocyte growth factor/scatter factor, its receptor, c-met, and tissue-type plasminogen activator during development of the murine olfactory system. J Neurosci 16:6933-6944.

Toni N, Buchs P-A, Nikonenko I, Bron CR, Muller D (1999) LTP promotes formation of multiple spine synapses between a single axon terminal and a dendrite. Nature 402:421-425.

Tsirka SE, Rogove AD, Bugge TH, Degen JL, Strickland S (1997) An extracellular proteolytic cascade promotes neuronal degeneration in the mouse hippocampus. J Neurosci 17:543-552.

Verrall S, Seeds NW (1989) Characterization of ${ }^{125}$ I-tissue plasminogen activator binding to cerebellar granule neurons. J Cell Biol 109:265-271.

Ware JH, DiBenedetto AJ, Pittman RN (1995) Localization of tPA mRNA in adult rat brain. Brain Res Bull 37:275-281.

Watson M, McElligott J (1983) 6-OH-DA induced effects upon the acquisition and performance of specific locomotor tasks in rats. Pharmacol Biochem Behav 18:927-934.

Zhuo M, Holtzman D, Li Y, Osaka H, DeMaro J, Jacquin M, Bu G (2000) Role of tissue plasminogen activator receptor LRP in hippocampal longterm potentiation. J Neurosci 20:542-549. 